\title{
BMJ Open Cost analysis of a mobile medical unit programme in Andhra Pradesh: a microcosting study protocol
}

\author{
Aakash Ashok Raikwar, ${ }^{1}$ Vishal Dogra (D) , ${ }^{1}$ Ashish Giri, ${ }^{1}$ Nitin Rathnam, ${ }^{2}$ \\ Shailendra Kumar Hegde ${ }^{3}$
}

To cite: Raikwar AA, Dogra V, Giri A, et al. Cost analysis of a mobile medical unit programme in Andhra Pradesh: a microcosting study protocol. BMJ Open 2021;11:e038191. doi:10.1136/ bmjopen-2020-038191

- Prepublication history and additional materials for this paper is available online. To view these files, please visit the journal online (http://dx.doi. org/10.1136/bmjopen-2020038191).

Received 02 March 2020 Revised 30 November 2020 Accepted 30 November 2020

Check for updates

(c) Author(s) (or their employer(s)) 2020. Re-use permitted under CC BY-NC. No commercial re-use. See rights and permissions. Published by BMJ.

${ }^{1}$ Research and Analytics, Piramal Swasthya Management and Research Institute, Hyderabad, India

${ }^{2}$ Public Private Partnerships and CSR Operations, Piramal Swasthya Management and Research Institute, Hyderabad, India

${ }^{3}$ Innovations, Piramal Swasthya Management and Research Institute, Hyderabad, India

Correspondence to

Dr Vishal Dogra;

vani1825@gmail.com

\section{ABSTRACT}

Introduction Offering primary healthcare through mobile medical units is an innovative way to reach the rural and the vulnerable population. With 292 mobile medical units, the Andhra Pradesh mobile medical unit (APMMU) programme is one of the largest health outreach programmes in rural India. However, India lacks reliable cost estimates for the health services delivered through mobile medical platforms. This study aims to estimate the unit cost of providing primary care services through mobile medical units in rural and tribal areas of Andhra Pradesh. Method and analysis Cost analysis of 12 mobile medical units will be undertaken. We will use the activity-based microcosting technique from the providers' perspective. A bottom-up approach will be used for cost estimation. Standardised tools will be used to collect data on activities and resources, and on the costs. Capital investments and recurrent costs will be measured and evaluated. Average unit costs, along with $95 \% \mathrm{Cls}$, will be reported. Sensitivity analysis will assess the cost estimate uncertainties and other cost assumptions.

Ethics and dissemination Piramal Swasthya Management Research Institute's ethics committee approved the study. The findings of the study will be disseminated through conference presentations, publications in peer-reviewed journals and advocacy with the national and state governments. This study will provide first-hand comprehensive cost estimates of provisioning primary healthcare services using mobile medical units in India.

\section{BACKGROUND}

Rural India accounts for nearly $69 \%$ of the total population but has only $26 \%$ of total hospital beds and $33 \%$ of the total healthcare professionals. ${ }^{1-3}$ Due to the unequal distribution of healthcare resources, the rural public health system in India remains inefficient.

The primary reasons for these inefficiencies include an inadequate number of health facilities, chronic human resource shortage and frequent drug stockouts, particularly in rural public health facilities. ${ }^{4}$ In 2017 , there was a $24 \%, 21 \%, 17.3 \%$ and $14.5 \%$ shortfall of government health facilities, medical doctors, nurses and pharmacists providing

\section{Strengths and limitations of this study}

The study applies existing microcosting methodology to the context of mobile medical units.

- The study samples a large and representative number of mobile medical units in rural and tribal Andhra Pradesh, India.

- The costing methodology is from the healthcare providers' perspective.

- Economic evaluation to study the effectiveness of mobile medical platforms in delivering primary healthcare services is suggested.

primary healthcare services, respectively. ${ }^{5-8}$ The average rate of absenteeism among the available staff is as high as $40 \%$, and people often have to travel more than $6 \mathrm{~km}$ to reach primary healthcare centres. ${ }^{9}$ Rural realities of steep terrain, infrequent transport services, illiteracy and economic constraints further impose barriers to health service utilisation and push people to seek care from the unorganised, informal and costly private healthcare sector. $^{10}$

Evidence suggests that only $11.5 \%$ of rural households sought primary level outpatient care (except for childbirth) in public health facilities, and the average medical expenditure of rural households is on the rise. For example, the average expenditure (per person per fortnight) for outpatient care in rural India has increased from US $\$ 29.4$ in 2004 to US $\$ 55$ in 2011. ${ }^{11} 12$ Provisioning of quality primary healthcare to rural people is, therefore, of utmost importance to improve access to healthcare services and protect them from catastrophic expenditures.

To make primary care available and accessible in rural areas, the Government of India rolled out Mobile Medical Unit (MMU) service under its flagship health programme, The 'National Health Mission'. The purpose of MMUs is to provide basic primary care 
services to the population living in remote and underserved areas close to their homes. ${ }^{13}$

An MMU has five-member staff (a doctor, nurse, lab technician, pharmacist and a driver) and is equipped with basic diagnostic equipment and medicines. Preventive, promotive, diagnostic, curative and referral healthcare are some of the services delivered through the network of MMUs. For service delivery, each MMU makes monthly, fixed day and date visits in the assigned villages as per the predefined route and schedule. Accredited social health activists, who are from the same village, inform the key informants and community members of their respective village a day prior to the MMU visit. ${ }^{13}$

MMUs today have gained widespread acceptance in India and there are 1569 functional MMUs operational in 29 states of India. ${ }^{14}$ The Government of Andhra Pradesh, in partnership with Piramal Swasthya Management and Research Institute, alone, ran a fleet of 292 MMUs till March 2019. ${ }^{15}$

There is enough evidence demonstrating the utility of MMU platform in facilitating access to healthcare services, reducing patients' cost (out of pocket expenditure), improving early detection of diseases and building referrals, especially, for minority groups. ${ }^{16-18}$ The model developed called the 'Knowledgeable Neighbours', by the Harvard Medical school has also shown effectiveness of MMUs in terms of screening for non-communicable diseases. ${ }^{17}$ However, despite extensive use, there are no reliable cost estimates for the health services delivered through such mobile medical platform. This information is important for policymakers, in addition to the evidence on the efficacy and effectiveness, in order to make informed investment decisions. Essentially the decisionmakers in different parts of the country face a dilemma when it comes to delivery of health services through mobile platforms. They often need to know the cost of operating mobile units from providers perspective, so as to convert it into a large comprehensive and scalable programme, balancing population needs, geographical coverage and available input resources such as budgets. In this study, we highlight the methodological details to estimate the unit cost of providing primary care services through MMUs in rural areas of Andhra Pradesh.

\section{AIMS AND OBJECTIVES}

The specific objective of the study is to estimate the cost of primary healthcare service delivery through the MMU platform from the providers' perspective in rural Andhra Pradesh, India.

\section{METHODS AND ANALYSIS \\ Study design}

This is a microcosting, cross-sectional mixed-method analytical study.

\section{Study period}

Originally study was planned from March 2020 to September 2020 however due to COVID-19, we plan to conduct this study after the pandemic. We assume data collection period to be 4 months from time of study initiation.

\section{Study settings}

We will conduct this study in rural Andhra Pradesh, where the APMMU programme is in operation. Andhra Pradesh is primarily a rural state with $66 \%$ of the population living in rural areas. ${ }^{18}$ The state is divided into two geographical areas ${ }^{1}$ Rayalaseema and ${ }^{2}$ Coastal Andhra Pradesh. Rayalaseema is the inland south-western part and Coastal Andhra Pradesh is on the east and north-east and has the second-most longest coastline in India.

\section{The APMMU programme}

The APMMU programme started in 2016, is once-amonth, fixed day, free,community outreach service at the village level. A network of 292 MMUs offer primary healthcare services (non-emergency) to beneficiaries of all ages in 13,523 villages across 13 districts of Andhra Pradesh state, India. The programme aims for equitable health access to the vulnerable and marginalised rural and tribal population. The programme scope includes providing promotive (health awareness camps), preventive (counselling of programme beneficiaries for a healthy lifestyle), diagnostic (random blood sugar, haemoglobin test, urine for protein, urine for sugar, malaria-rapid diagnostic test, urine pregnancy test), therapeutic (medicine prescription) and referral services (referral to nearby government health facilities for further diagnosis, confirmation and or treatment). Pregnant mothers and children get antenatal and postnatal check-ups. In addition to providing medical services, the MMU also conducts chlorination of the local water bodies in the village. The MMUs remain operational 24 days a month and deliver primary healthcare services to the rural and tribal population residing at least $5 \mathrm{~km}$ away from any public health facility. An MMU covers a village of approximately 1,500 population each in the morning (10:00 AM to 1:30 PM) and in the afternoon (2:30 PM to 5:30 PM) everyday. Overall 20,000 beneficiaries are served for various acute and chronic health conditions in a day. There is no prior booking system and anyone can walk-in for availing the programme services. The programme service delivery is uniform across all MMUs and beneficiaries are not prioritised as this is a non-emergency healthcare programme.

Additionally, every MMU is fitted with a global positioning system (for real-time location tracking), a biometric device (for staff attendance), an electronic medical record system and 51 types of medical instruments. The nurse has a laptop while the laboratory technician and the pharmacists have a tablet each to record patient data. The nurse uploads and synchronises the day's data onto a central server at the day's end. Data are directly fed into government dashboards and aggregated service utilisation information such as the number of patients served, and types of health conditions among 
beneficiaries and so on are presented on a near-real-time basis.

\section{Patient and public involvement}

No patients will be involved in the study.

\section{Sampling and sample size}

We will use a three-step multistage sampling.

\section{Stage 1}

Listing of all districts in Andhra Pradesh. Based on the difficulty score $(\beta)$-related to programme implementation, all districts will be categorised into 'low (20.0-26.9)', 'medium (27.0-35.0)' and 'high (35.1-50)' difficulty districts. The difficulty score $(\beta)$ is an estimate of the difficulty involved in implementing the MMU project in different geographical areas. The difficulty score $(\beta)$ is calculated based on four variables namely,percentage of tribal population, percentage rural population, population density and MMU coverage in the village.

Difficulty score calculation: we constructed $\beta$ by weighting the following variables-

1. Population density score of district (density of population per square kilometre* 0.3 ).

2. Tribal score of district (\% of tribal population to total district population*0.3).

3. Rural score of district (\% of rural population to the total district population*0.2).

4. The coverage of MMU districts wise (number of villages in district divided by number of MMUs and then multiplied by weightage factor 0.2 ).

Summation of the four scores above gives the beta score.

The weighing factors $(0.3,0.3,0.2$ and 0.2 as mentioned above) were developed in consultation with health experts in programme management (districts/state programme managers) and the local health authorities (nodal district/state programme officer).

\section{Stage 2}

We will randomly select two districts from each of the three categories described in stage 1 . This will give us a total of six districts.

\section{Stage 3}

All MMUs present in these six districts will be listed. We will randomly select two MMUs per district, whose average distance travelled in a month is within two SDs of the average distance travelled by all MMUs in the district. One MMU each, that satisfy the above criteria, will be selected from the tribal and rural area. The main advantage of taking this method is that we assume distance travelled by the MMU and geographical terrain will also reflect on the unit cost of services delivered. ${ }^{19}$

\section{Sample size}

Cost analysis is the first step of partial economic evaluation. ${ }^{20}$ We will select 12 MMUs from the six districts,

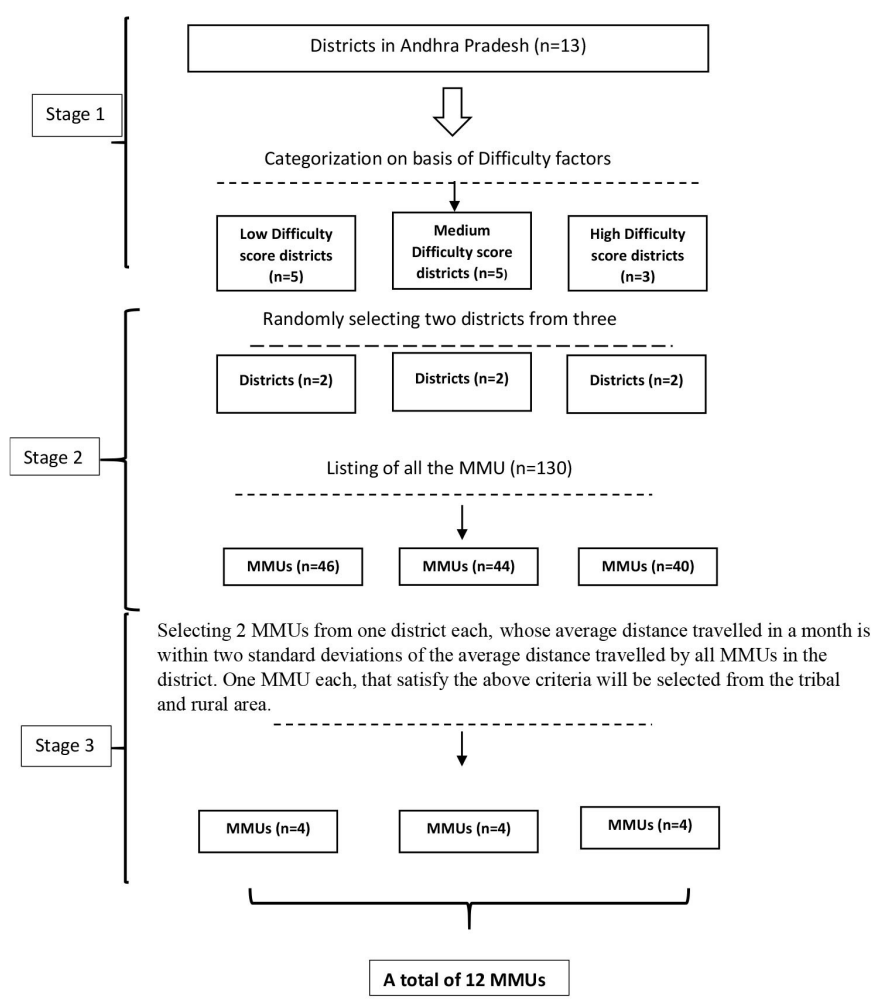

Figure 1 Schematic representation of sampling. MMU, mobile medical unit.

which is around $10 \%$ of the total MMUs in the selected six districts (figure 1).

\section{Costing methodology}

The activity-based microcosting approach of cost analysis will be applied. The activity-based costing has high granularity as it enlists, quantifies and values every single item required in the production of service. ${ }^{21}$

\section{Types of cost}

We will collect data on capital and recurrent resources (table 1) used for delivering mobile health services in the year 2019-2020. The capital cost will include building space, equipment/appliances, the vehicle, including the start-up cost (cost incurred to initiate any new activity

Table 1 Capital and recurring cost for MMU project in rural Andhra Pradesh (2019-2020)

\begin{tabular}{lc}
\hline $\begin{array}{l}\text { Capital cost (online } \\
\text { supplemental annexure 1) }\end{array}$ & $\begin{array}{l}\text { Recurring cost (online } \\
\text { supplemental annexure 2) }\end{array}$ \\
\hline $\begin{array}{l}\text { Building/rental space, } \\
\text { equipment/appliances, } \\
\text { vehicle }\end{array}$ & $\begin{array}{l}\text { Human resource, medicines, } \\
\text { consumables, diagnostics }\end{array}$ \\
$\begin{array}{l}\text { Start-up activities: activities } \\
\text { that last until the end of the } \\
\text { project }\end{array}$ & $\begin{array}{l}\text { Overheads for example, office } \\
\text { expenditure, maintenance, bills } \\
\text { travel, etc. }\end{array}$ \\
$\begin{array}{l}\text { One-time activity: training, } \\
\text { workshops, etc. }\end{array}$ & $\begin{array}{l}\text { Training, workshops and } \\
\text { information, education and } \\
\text { communication activities }\end{array}$ \\
\hline
\end{tabular}

MMU, mobile medical unit. 
during the reference period). Trainings not repeated within 1 year will be considered as capital costs. Staff salaries, consumables (drugs), fuel (diesel/petrol) and vehicle maintenance cost will fall under the recurrent costs.

\section{Data collection}

We will use a mixed-method approach employing a primary survey (using a quantitative tool and qualitative interviews) and secondary review of retrospectively collected routine programme data.

\section{Primary survey}

The primary survey will collect data from two levels, that is, the programme administration level (state, regional and district and MMU project head office) and the MMU level (field). We will use the Facility Costing Tool (FCT) (online supplemental annexure 1) and Mobile Medical Unit Assessment tool (MMUA) (online supplemental annexure 2) at the programme administration level and MMU level, respectively. The MMUA and FCT tool will collect data on the quantities of items such as human resources, drugs and consumables, medical and non-medical items and qualitative responses like the time required to perform different activities, number of items required to perform the activities through open-ended questions. We will interview the expert panel using a structured interview schedule (online supplemental annexure 3 ) to arrive at the allocation ratio and time spent on the production of shared services.

\section{Secondary review}

The secondary data will be extracted from the routine administration (patient load at MMUs, types of services used) and financial reports (purchasing prices of the capital and recurrent items, life year of the capital items, utility expenditure) of the programme.

Since we plan to use the bottom-up approach, therefore, the cost estimation exercise using MMUA tool at MMU level will be first completed. The FCT will be used at the regional administration, district administration and finally at the state level.

The collected data will allow us to partition the cost into different levels (MMU level, district level, regional and state level) and to align with the WHO's Choosing Intervention that are cost-effective methodology. ${ }^{22}$ Both tools will be used to estimate the various quantities of inputs like human resources, overheads, utility, building, equipment use and cost. This will ensure that with every level of costing, our estimate becomes more precise. ${ }^{21}$

Table 2 below shows the number of MMU administrative facilities and key informants to be costed and interviewed at programme implementation and administration level for the primary data collection.

Table 3 below gives an overview of cost elements, data sources, allocation to the services and the tools to be referred.
Table 2 Costing survey on various level with key informant estimate

\begin{tabular}{llcll}
\hline Costing level & $\begin{array}{l}\text { Number } \\
\text { (s) }\end{array}$ & $\begin{array}{l}\text { Number of } \\
\text { personnel } \\
\text { involved in } \\
\text { the survey }\end{array}$ & $\begin{array}{l}\text { Number } \\
\text { of human } \\
\text { resources in } \\
\text { the survey }\end{array}$ & $\begin{array}{l}\text { Type of } \\
\text { data to be } \\
\text { collected }\end{array}$ \\
\hline $\begin{array}{l}\text { MMUs (field } \\
\text { level) }\end{array}$ & 12 & 5 & 60 & $\begin{array}{l}\text { Quantitative } \\
\text { and qualitative }\end{array}$ \\
\hline $\begin{array}{l}\text { Programme } \\
\text { office (state) } \dagger\end{array}$ & 1 & 6 & $15-20$ & $\begin{array}{l}\text { Quantitative } \\
\text { and qualitative }\end{array}$ \\
$\begin{array}{l}\text { Regional } \\
\text { offices } \\
\text { (regions) } \dagger\end{array}$ & 2 & 3 & $20-22$ & $\begin{array}{l}\text { Quantitative } \\
\text { and qualitative }\end{array}$ \\
\hline $\begin{array}{l}\text { Central drug } \\
\text { store (district) } \dagger\end{array}$ & 1 & 2 & $2-3$ & Quantitative \\
\hline $\begin{array}{l}\text { Head office } \\
\text { (state) } \dagger\end{array}$ & 1 & $4-6$ & $4-6$ & $\begin{array}{l}\text { Quantitative } \\
\text { and qualitative }\end{array}$ \\
\hline $\begin{array}{l}\text { District offices } \\
\text { (district) } \dagger\end{array}$ & 6 & $3-4$ & $10-14$ & $\begin{array}{l}\text { Quantitative } \\
\text { and qualitative }\end{array}$ \\
\hline \begin{tabular}{l} 
Total \\
\hline
\end{tabular} & 17 & $23-26$ & $100-115$ & \\
\hline
\end{tabular}

*Programme implementation level.

†Programme administration level.

MMU, mobile medical unit.

\section{Study outcomes}

The study will clearly differentiate between the capital and recurrent costs (detailed in online supplemental annexures 1 and 2). Once we have capital and recurrent costs, we will use the step-down approach for the allocation of the cost in terms of various services provided under the MMU platform. Study outcomes are detailed in online supplemental annexure 4 .

\section{Data management and analysis}

Two field researchers (graduate in social science or an associated field) will receive training in costing methodologies and data collection procedures. The training will be followed by hands-on piloting of the tools in the field. The standard training manual of the WHO on cost analysis will be used. ${ }^{23}$

We will collect information on the price and quantity of items consumed within a given input systematically. We will prepare a list of items (types and quantities) and the monetary value of each item based on their market prices. Adjustment to prices will be done if the prices of government purchased resources (drugs, consumables, equipment etc) are skewed compared to the actual market prices. We consider resources purchased by the government skewed towards the government because the government purchases in bulk and from the big buyers, giving government bargaining power for overall lower prices. And hence, we will adjust the cost of the items to reflect the true market value. The annual cost of each type of input will be calculated by combining/multiplying the unit price of services by the number of units consumed in a year.

All cost calculations will be done from the providers' perspective using a bottom-up approach. We will not measure patient-level direct or indirect costs. All prices 
Table 3 Data points for allocation of cost, data sources (tools used FCT)

\begin{tabular}{|c|c|c|c|c|}
\hline $\begin{array}{l}\text { Data points at the MMU/ } \\
\text { admin level }\end{array}$ & Data elements & Data sources & Allocation & $\begin{array}{l}\text { Reference to the } \\
\text { annexure and section }\end{array}$ \\
\hline Salary & $\begin{array}{l}\text { Number of hours working } \\
\text { in the day, working days in } \\
\text { a year, leave etc }\end{array}$ & Payslips & $\begin{array}{l}\text { The proportion of time spent } \\
\text { on MMU-related work through } \\
\text { timesheet record }\end{array}$ & $\begin{array}{l}\text { Expert panel interview } \\
\text { schedule }\end{array}$ \\
\hline Overheads & $\begin{array}{l}\text { Electricity, water, internet, } \\
\text { audit expense }\end{array}$ & Office records & $\begin{array}{l}\text { The proportion of overheads } \\
\text { used for MMU services }\end{array}$ & MMUA and FCT \\
\hline Equipment & Medical, non-medical & $\begin{array}{l}\text { Facility survey and } \\
\text { non- consumable } \\
\text { registers }\end{array}$ & $\begin{array}{l}\text { The proportion of time spent } \\
\text { on different activities/work by } \\
\text { concerned staff }\end{array}$ & $\begin{array}{l}\text { MMUA, FCT and } \\
\text { expert panel interview } \\
\text { schedule }\end{array}$ \\
\hline Travel & $\begin{array}{l}\text { MMU outreach, } \\
\text { diesel monthly cost, } \\
\text { maintenance }\end{array}$ & Travel diaries & $\begin{array}{l}\text { The proportion of time spent } \\
\text { on different MMU work }\end{array}$ & $\begin{array}{l}\text { MMUA, FCT and } \\
\text { expert panel interview } \\
\text { schedule }\end{array}$ \\
\hline $\begin{array}{l}\text { IEC costs (banners, wall } \\
\text { paintings, etc) }\end{array}$ & Print material, audio-visual & Office records & $\begin{array}{l}\text { The proportion of patients } \\
\text { among total population } \\
\text { benefiting from IEC }\end{array}$ & MMUA and FCT \\
\hline $\begin{array}{l}\text { Training (honorarium, travel, } \\
\text { space, equipment and time } \\
\text { costs) }\end{array}$ & $\begin{array}{l}\text { Software training, } \\
\text { induction training, } \\
\text { refresher training in MMU }\end{array}$ & Office records & $\begin{array}{l}100 \% \text { only for intervention } \\
\text { area or proportion of training } \\
\text { on MMU }\end{array}$ & MMUA and FCT \\
\hline
\end{tabular}

FCT, facility costing tool; IEC, information, education and communication; MMU, mobile medical unit.

will be converted to the level of prices in 2020 using the gross domestic product deflators. ${ }^{24}$

Data analysis will be done to estimate the unit cost of delivering primary care services through MMUs.

The results will be reported adopting the Global Health Cost Consortium's results reporting format. ${ }^{25}$ The final cost estimates (in rupees) will be converted to the US dollars using exchange rate/purchasing power parity for international comparison and generalisability. ${ }^{26}$

For costing the inflation adjustment will be made for making it comparable concerning the year of costing. ${ }^{24}$ Uncertainty in all the cost estimation studies is inherently present. To counter these uncertainties in cost estimation, we will ensure that the magnitude of uncertainty is kept at an acceptable range by using univariate sensitivity analysis. ${ }^{27}$ There is a presence of price variability of items like drugs, consumables and so on, and product differentiation is very common in the market. ${ }^{28}$ And in some cases, it will be difficult to get the prices of the items due to various reasons. The univariate sensitivity analysis will be applied to changing cost and the volume of beneficiaries to assess level of coverage of APMMU services. Further, the base value of salaries, price of equipment, building cost, rental prices and assumptions on time allocation will be varied by $25 \%$ on both sides. If the prices of drugs and consumables show wide variation, we will vary them by $90 \%$ on lower limit to $100 \%$ on upper limit on the average price of the drugs and consumables prevailing in the costing year (2020-2021). We will also estimate the sensitivity of the annual cost and unit cost for providing overall MMU services to variations in discount rates at $3 \%$ and $10 \% .{ }^{29}$
Data will be collected on paper and will be entered into Microsoft excel 2016. The principal investigator will access the data files weekly for quality assurance. Logic and range checks will be used to minimise errors in the data entry process and identifying missing data or problem with the completed data. The paper and electronic data will be preserved for 3 years from the date of study completion.

\section{ETHICAL CONSIDERATIONS AND STUDY DISSEMINATION}

Piramal Swasthya Management Research Institute ethics committee approved the research study (PSMRI/2019/10). There is no contact with patients and all data are collected from staff members and healthcare workers. Written consent will be taken before conducting any interviews. The findings of the study will be disseminated through conference presentations, publications in peer-reviewed journals and advocacy with the national and state governments.

\section{STUDY STATUS}

Ethical approval and training of data collectors have been completed in January 2020. However, due to COVID19 , we anticipate data collection beginning not before November 2020.

\section{SIGNIFICANCE OF THE STUDY}

This study will give unit cost estimates of offering various primary care services like general medicine, gynaecology and obstetrics care through MMUs in rural and 
tribal areas of Andhra Pradesh. Furthermore, it will also provide insights into the difference in resources used and costs incurred. Thereby, aiding in the planning of quality care and improving health systems performance by increasing efficiency. ${ }^{30}$ This study could potentially provide a rationale for either scaling up, scaling down or discontinuing the use of MMU as a model for healthcare service delivery in far-flung and difficult to reach areas of India. This study will generate cost estimates for different components of the MMU programme like capital, recurrent and total cost. This will help in the identification of efficient and inefficient services that can be either scaled up, scaled-down or removed.

\section{Twitter Vishal Dogra @drvishal1825}

Contributors AR, VD and SKH conceived the study concept. VD contributed to the preparation of the protocol and study tools. AG helped in writing the protocol. AR, VD, AG and SKH contributed to the development of research methods. NR contributed in refining first draft and is responsible for program management. All authors read and approved the final protocol version.

Funding The authors have not declared a specific grant for this research from any funding agency in the public, commercial or not-for-profit sectors.

Competing interests None declared.

Patient consent for publication Not required.

Provenance and peer review Not commissioned; externally peer reviewed.

Supplemental material This content has been supplied by the author(s). It has not been vetted by BMJ Publishing Group Limited (BMJ) and may not have been peer-reviewed. Any opinions or recommendations discussed are solely those of the author(s) and are not endorsed by BMJ. BMJ disclaims all liability and responsibility arising from any reliance placed on the content. Where the content includes any translated material, BMJ does not warrant the accuracy and reliability of the translations (including but not limited to local regulations, clinical guidelines, terminology, drug names and drug dosages), and is not responsible for any error and/or omissions arising from translation and adaptation or otherwise.

Open access This is an open access article distributed in accordance with the Creative Commons Attribution Non Commercial (CC BY-NC 4.0) license, which permits others to distribute, remix, adapt, build upon this work non-commercially, and license their derivative works on different terms, provided the original work is properly cited, appropriate credit is given, any changes made indicated, and the use is non-commercial. See: http://creativecommons.org/licenses/by-nc/4.0/.

ORCID iD

Vishal Dogra http://orcid.org/0000-0001-9725-5699

\section{REFERENCES}

1 Chadramouli C. Registrar general \& census commissioner. Provisional population totals rural urban distribution. Census of India 2011;1:1-19.

2 State/UT wise Number of Government Hospitals and beds in rural and urban areas (including community health centres) In India as on 1st January 2013 [online]. Available: https://data.gov.in/resources/ stateut-wise-number-government-hospitals-and-beds-rural-andurban-areas-including [Accessed 9 Jan 2020].

3 Karan A, Negandhi H, Nair R, et al. Size, composition and distribution of human resource for health in India: new estimates using national sample survey and registry data. BMJ Open 2019;9:e025979.

4 Dalal K, Dawad S. Non-utilization of public health care facilities: examining the reasons through a national study of women in India. Rural Remote Health 2009;9:1178.

5 Shortfall in health infrastructure [online]. Available: https://data. gov.in/catalog/shortfall-health-infrastructure-0?filters \%5Bfield catalog_reference $\% 5 \mathrm{D}=95726 \&$ format=json\&offset $=0 \&$ limit $=6$ \&sort $\%$ 5Bcreated\%5D=desc [Accessed 9 Jan 2020].

6 State/ UT-wise allopathic doctors at primary health centres as on 31-03-2017 [online]. Available: https://data.gov.in/resources/state- ut-wise-allopathic-doctors-primary-health-centres-31-03-2017 [Accessed 21 Jan 2020].

7 State/ UT-wise nursing staff at primary health centres (PHCs) and community health centres (CHCs) as on 31st March 2017 [online] Available: https://data.gov.in/resources/state-ut-wise-nursing-staffprimary-health-centres-phcs-and-community-health-centres-chcs [Accessed 9 Jan 2020].

8 State/ UT-wise pharmacists at primary health centres (PHCs) and community health centres (CHCs) as on 31-03-2017 [online]. Available: https://data.gov.in/resources/state-ut-wise-pharmacistsprimary-health-centres-phcs-and-community-health-centres-chcs31 [Accessed 9 Jan 2020].

9 Sharma DC. India still struggles with rural doctor shortages. Lancet 2015;386:2381-2.

10 Gabert R, $\mathrm{Ng} \mathrm{M}$, Sogarwal R, et al. Identifying gaps in the continuum of care for hypertension and diabetes in two Indian communities. BMC Health Serv Res 2017;17:1-11.

11 Government of India M of statistics and programme. Key indicators of social consumption in India on health, national sample survey round 71st. New Delhi, 2014.

12 Out of pocket health spending has risen in rural India: study [online]. Available: https://www.downtoearth.org.in/news/out-of-pockethealth-spending-has-risen-in-rural-india-study-35613 [Accessed 10 Jan 2020].

13 Ministry of Health and Family Welfare G of I. Operational guidelins forMobile medical units. New Delhi, 2015.

14 State/ UT-wise number of sub divisional hospital, District hospital and mobile medical units functioning as on 31-03-2017 [online] Available: https://data.gov.in/resources/state-ut-wise-numbersub-divisional-hospital-district-hospital-and-mobile-medical-units [Accessed 10 Jan 2020]

15 The Hindu. CM launches 'Chandranna Sanchara Chikitsa' [online], 2016. Available: https://www.thehindu.com/news/cities/Vijayawada/ cm-launches-chandranna-sanchara-chikitsa/article8501224.ece [Accessed 25 Apr 2019].

16 Edgerley LP, El-Sayed YY, Druzin ML, et al. Use of a community mobile health van to increase early access to prenatal care. Matern Child Health J 2007;11:235-9.

17 Hill C, Zurakowski D, Bennet J, et al. Knowledgeable neighbors: a mobile clinic model for disease prevention and screening in underserved communities. Am J Public Health 2012;102:406-10.

18 AP Demography [online]. Available: https://www.ap.gov.in/wpcontent/uploads/2016/01/2-AP-Demography.pdf [Accessed 19 Dec 2018].

19 Fiedler JL, Dado DR, Maglalang H, et al. Cost analysis as a vitamin A program design and evaluation tool: a case study of the Philippines. Soc Sci Med 2000;51:223-42.

20 Drummond MF, Sculpher MJ, Claxton K. Methods for the economic evaluation of health care programmes. 4th edn. Oxford, 2015: 1-461.

21 Chapko MK, Liu C-F, Perkins M, et al. Equivalence of two healthcare costing methods: bottom-up and top-down. Health Econ 2009;18:1188-201.

22 Edejer T, Baltussen R, Adam T. Who guide to cost-effectiveness analysis. who library cataloguing-in-publication data scaling 2010: 1-329.

23 Creese A, Parker D. Cost analysis in primary health care: a training manual for programme managers [online]. World Health Organization, 1994. http://apps.who.int/iris/bitstream/10665/40030/1/9241544708. pdf?ua $=1$

24 Kumaranayake L. How to do (or not to do)... The real and the nominal ? Making inflationary adjustments to. Health Policy Plan 2000;15:230-4

25 Global Heath Cost Consortium [online]. Available: https://ghcosting. org/pages/standards/appendices/principles_and_methods reporting_checklist [Accessed 20 Jan 2020].

26 Prices and purchasing power parities (PPP) - OECD [online]. Available: https://www.oecd.org/sdd/prices-ppp/ [Accessed 10 Jan 2020].

27 Gray AM, Clarke PM, Jane L. Applied methods of cost-effectiveness analysis in health care. 1st edn. Oxford University Press, 2011: 1-313.

28 Hutton G, Baltussen R. Cost valuation in resource-poor settings. Health Policy Plan 2005;20:252-9.

29 Gupta SK. Proposed pharmacoeconomics guidelines for india (PEG-I) ISPOR INDIA CHAPTER ISPOR India Chapter [online]. Available: www.isporindia.com [Accessed 24 Sep 2020].

30 Mittmann N, de Oliveira C. Importance of cost estimates and cost studies. Curr Oncol 2016;23:6. 